\title{
CLOUD ACTIVITY ON MARS NEAR THE EQUINOX: COMPARISON OF THE 1937 AND 1969 OPPOSITIONS
}

\author{
G. de VAUCOULEURS
}

Department of Astronomy, University of Texas at Austin, Austin, Tex., U.S.A.

\begin{abstract}
Four classes of manifestations of cloud activity observed in 1937 and 1969 near the autumn equinox of the northern hemisphere $\left(165^{\circ}<L_{s}<192^{\circ}\right)$ are discussed: (1) formation of the north polar haze cap, (2) unusual cloud systems on the disk, (3) recurrent or persistent cloud activity at the sunset limb, (4) clouds seen in projection above the sunrise terminator.
\end{abstract}

This paper compares various manifestations of cloud activity on Mars near the equinox observed by the author near the corresponding oppositions of 1937 and 1969. Figure 1 shows the ranges of heliocentric longitudes $L_{s}$ covered by the observations available at several oppositions, in particular 1937 and 1969; other relevant data including opposition dates (crosses), perigee dates and maximum apparent diameter, and the times of the Mariner 6 and 7 encounters (small circles) are also given. Figures $2 \mathrm{a}$ and $2 \mathrm{~b}$ show

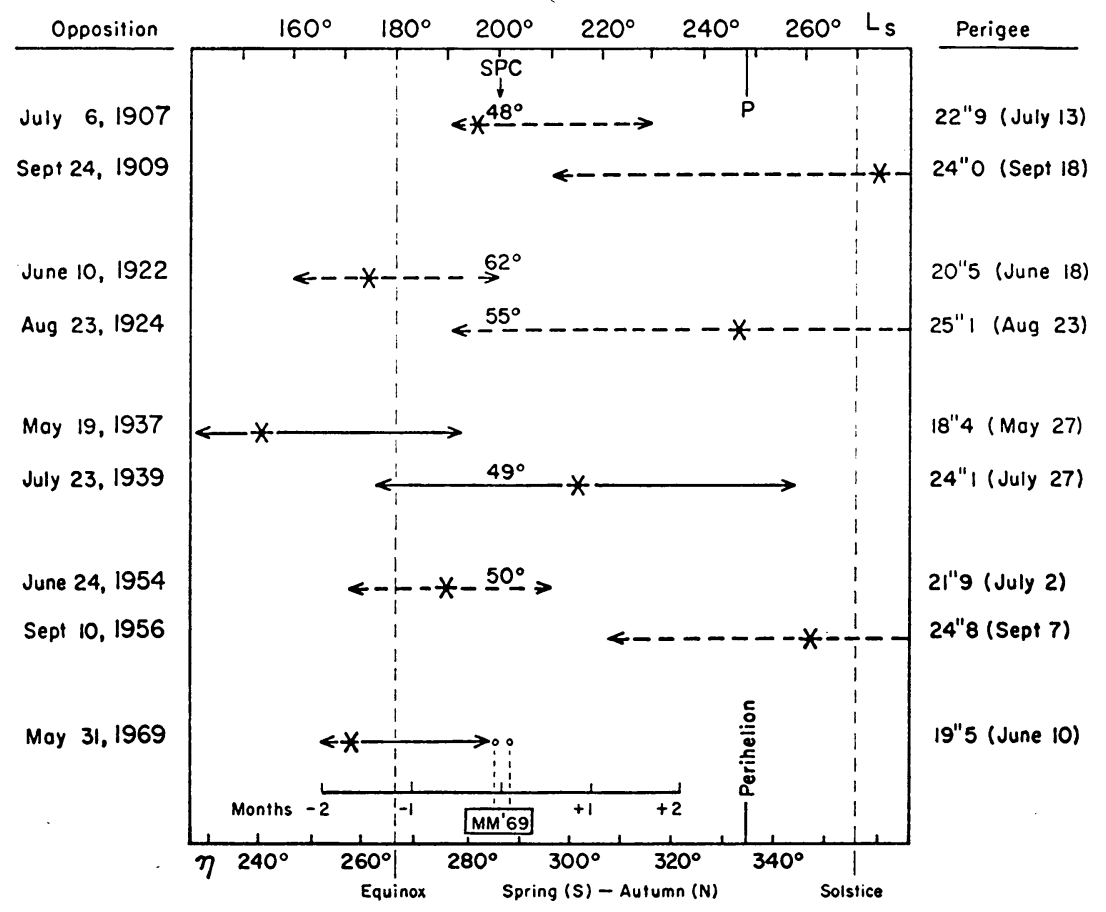

Fig. 1. Observations of Mars at several oppositions. Arrows indicate the range of heliocentric longitudes $\left(\eta, L_{s}\right)$ covered by the author's observations (full line) and of others (dashed). Opposition dates (left and crosses), and perigee apparent diameter (right) are given. Mariner 6, 7 encounter dates and areocentric diameter of south polar surface cap are also shown. 


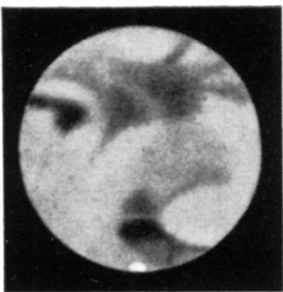

May 3

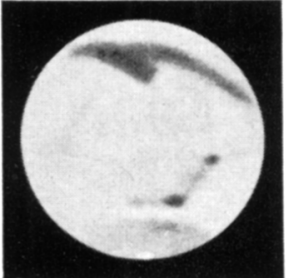

Moy 23

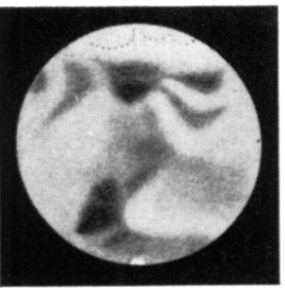

June I

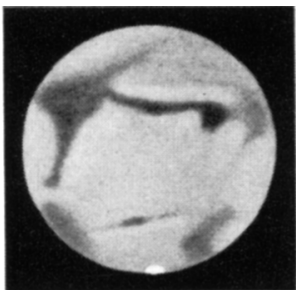

Moy 6

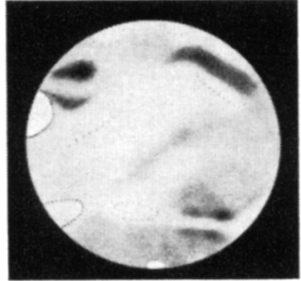

$120^{\circ}$

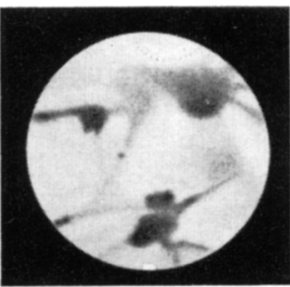

June 4

$25^{\circ}$

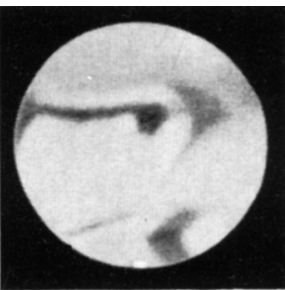

May 6.

$356^{\circ}$

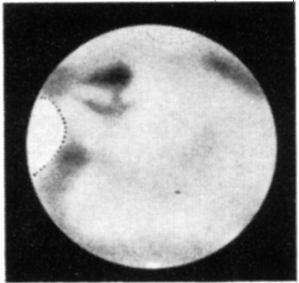

$99^{\circ}$

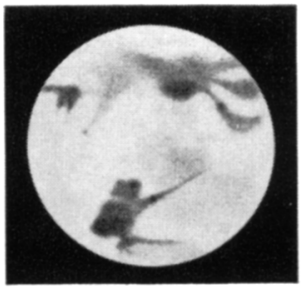

Moy 28

June 4

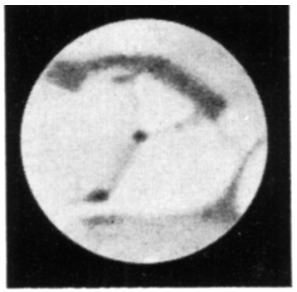

Moy 23

$205^{\circ}$

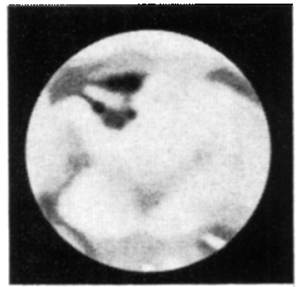

Moy 29

$10 e^{\circ}$

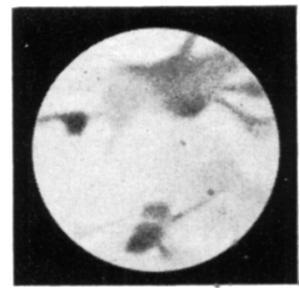

44. June 5

Opposition date 1937 May 19. Perigee diameter 18 " 4 (May 27) Heliocentric longlfudes $L_{S}=143^{\circ}$ to $160^{\circ}$ Latifude of center of disk $D_{E}=+9^{\circ}$ to $+15^{\circ}$

Fig. 2a. Observations of Mars in 1937. (18-cm refractor, Observatoire de la Société Astronomique de France, Paris.) 


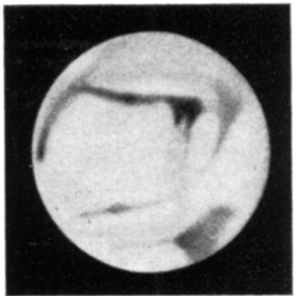

June 12

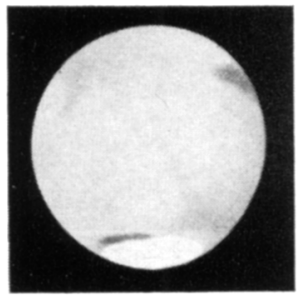

July 2

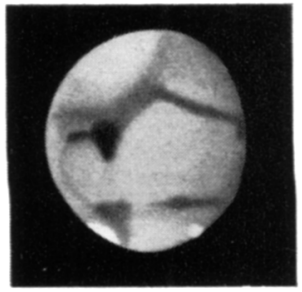

wily 20

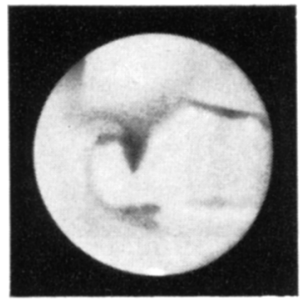

June 14

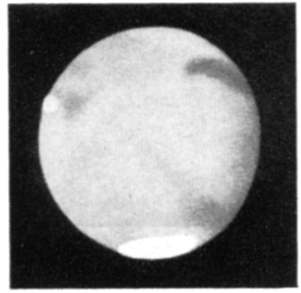

July 3

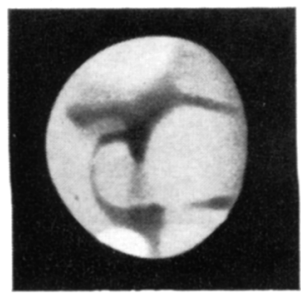

July 22

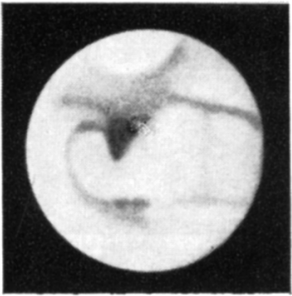

$305^{\circ}$

June 15

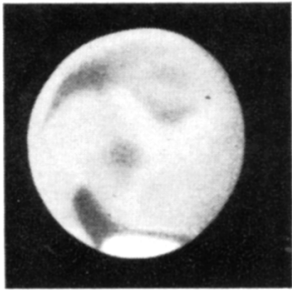

July 8

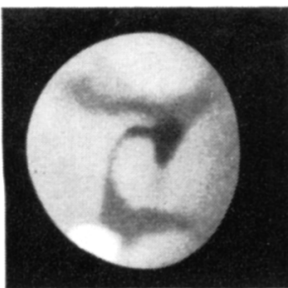

July 24

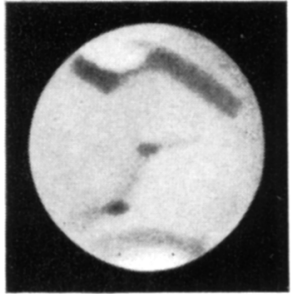

June 25

$200^{\circ}$

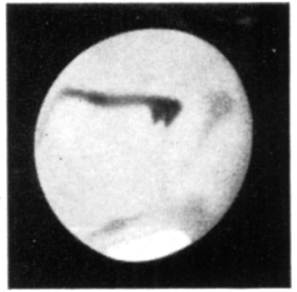

July 16

$0^{\circ}$

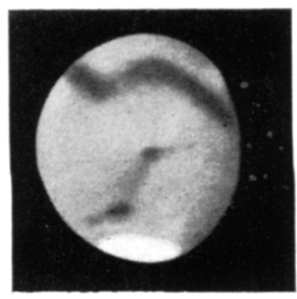

Aug 2

$200^{\circ}$

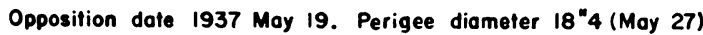

Heliocentric longifudes $L_{s}=164^{\circ}$ to $192^{\circ}$

Latifude of center of disk $D_{E}=+14^{\circ}$ to $+17^{\circ}$

Fig. 2b. 
24 drawings made in $1937\left(143^{\circ}<L_{s}<192^{\circ}\right)$ with an $18-\mathrm{cm}$ refractor $(\times 180$ to $\times 365)$ in Paris. Figures 3a, 3b, and 3c show 38 drawings made in $1969\left(165^{\circ}<L_{s}<191^{\circ}\right)$ with a $23-\mathrm{cm}$ refractor $(\times 370)$ in Austin. South is at the top. In 1937 the observations were made in 'white' light $\left(\lambda_{e} \simeq 0.56 \mu\right)$; in 1969 an orange filter $\left(\mathrm{Wr} 21, \lambda_{e} \simeq 0.59 \mu\right)$ was used, supplemented by inspections through green $\left(\mathrm{Wr} 58, \lambda_{e} \simeq 0.52 \mu\right)$ and red (Wr25, $\lambda_{e} \simeq 0.63 \mu$ ) filters to help in the discrimination of atmospheric and surface phenomena.

Cloud phenomena observed visually fall into 4 classes: (1) formation of the haze cap over the north polar regions near the autumn equinox, (2) unusual cloud systems on the disk, (3) persistent or recurrent cloud activity at the sunset limb, (4) clouds seen in projection above the sunrise terminator.

\section{Formation of the North Polar Haze Cap}

This is a seasonal phenomenon which repeats with remarkable regularity from year to year. Near the end of summer the north polar snow cap is very small (diam. $<5^{\circ}=300$ $\mathrm{km}),{ }^{*}$ often difficult to see and occasionally invisible in poor seeing, but the atmosphere is quite clear and transparent over the polar regions. This situation prevailed in 1937 until June $15\left(L_{s}=166^{\circ}\right)$ and in 1969 until June $14\left(L_{s}=173^{\circ}\right)$. The atmospheric haze over the north polar regions was first observed on June $25\left(L_{s}=170^{\circ}\right)$ in 1937 and on June $13\left(L_{s}=172^{\circ}\right)$ in 1969 . Thus, visible condensation of the polar haze cap begins at $L_{s} \simeq 171^{\circ}$ or about 2 weeks before the equinox. For a period of several weeks the polar haze is evidently still tenuous, and varies greatly in extent and density. Note the day-today variations in Figures $3 b$ and $3 c$. Frequently the brightest part is not centered above the pole but forms over preferred areas at the Western limb (i.e. in the afternoon); note especially the striking repetition of a bright whitish cloud formation over Utopia (lower left) on July $22-24,1937\left(L_{s}=186^{\circ}-188^{\circ}\right)$ and July 6-10, $1969\left(L_{s}=185^{\circ}-187^{\circ}\right)$. During this period immediately following the equinox a great deal of variable cloudiness was observed in 1969 over the northern sub-polar areas extending from Mare Acidalium (June 28-30) through Dioscuria-Cydonia (July 1-5) to Umbra-Utopia (July 5-9) and Panchaia-Lemuria (July 10-16). Note in particular the broken-up cloudy area covering part of Mare Acidalium on June 30 (compare with clear views of June 28, 29), another concealing Arethusa Lacus and the Callirrhoe streak on July 2 and 3 (compare with July 4), the small isolated cloud mass north of Coloe Palus on July 5 (compare with July 4), the interruption of Casius by a complex cloud system extending also to the East over Aetheria and West over the north tip of Isidis Regio on July 8 (compare with July 7 and 10, a remnant of the western mass was still present on the 9th), finally notice the bright pointed prominence of the main north haze cap over Herculis Pons on July 15 (compare with July 16).

It is important to note that these cloud masses and haze-covered areas are whitish and become always more conspicuous through a green filter, they should not be confused (as some observers have done in recent years) with the normal brighter areas of

* Corrected for diffraction and seeing ( 8 apparent). 


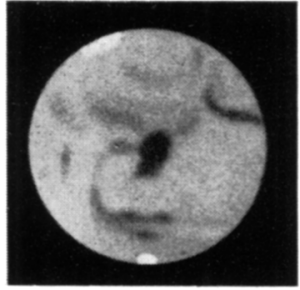

Moy 31

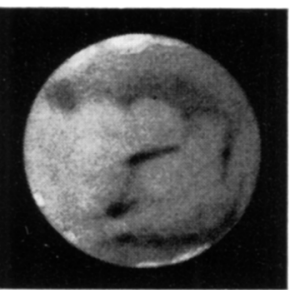

June 7

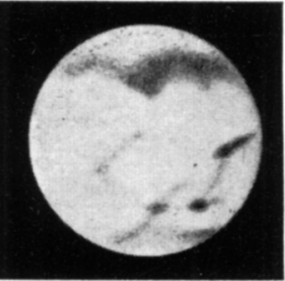

June II

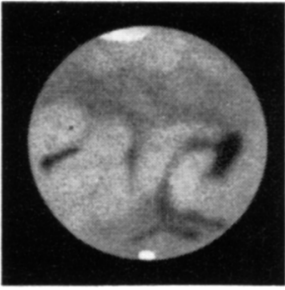

June 1

$250^{\circ}$

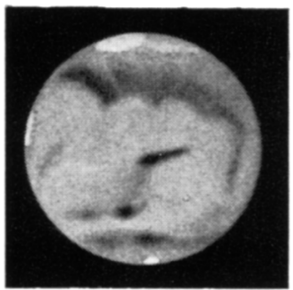

June 8

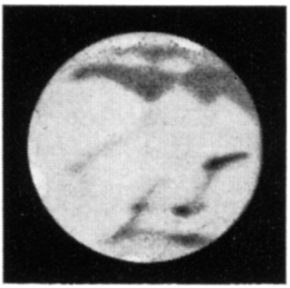

June 12

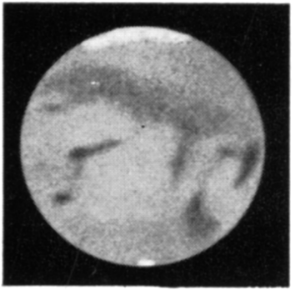

June $\cdot 5$

$226^{*}$

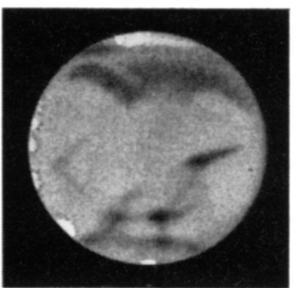

June 9

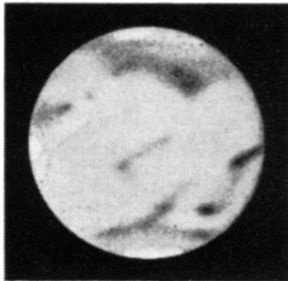

June 13

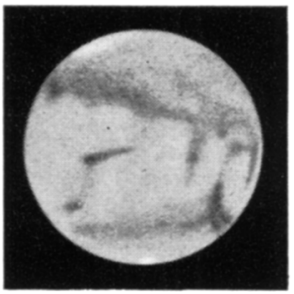

Jume 6

$219^{\circ}$

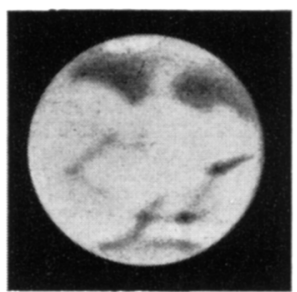

June 10

$164^{\circ}$

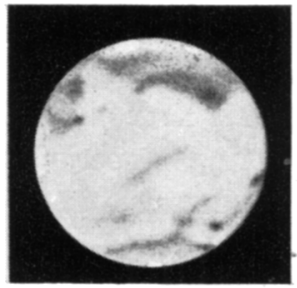

June 14

$132^{\circ}$

Opposition date 1969 May 31. Perigee diameter $19^{\prime \prime} 5$ (June 9)

Heliocentric longifudes $L_{s}=165^{\circ}$ to $173^{\circ}$

Latifude of center of disk $D_{E}=+7^{\circ}$ to $10^{\circ}$

Fig. 3a. Observations of Mars in 1969. (23-cm refractor, University of Texas Students' Observatory, Austin.) 


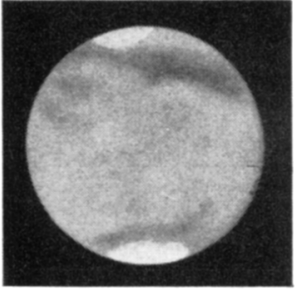

June 19

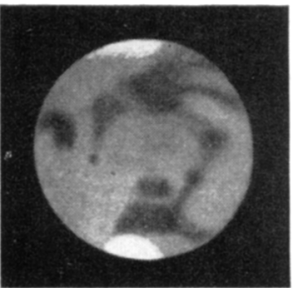

June 26

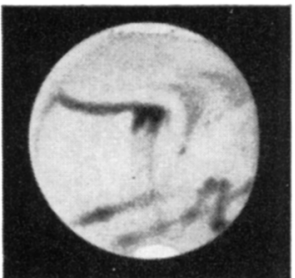

June $\mathbf{3 0}$

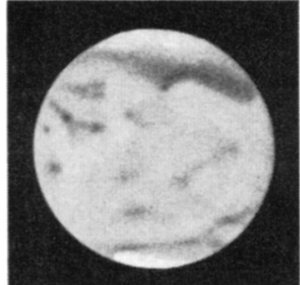

June 20

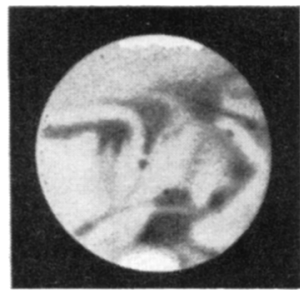

June 28

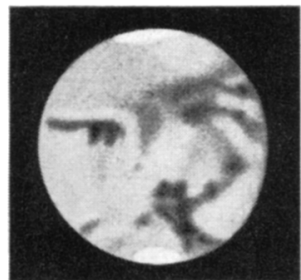

$7^{\circ}$ June 30 $123^{\circ}$

June 21

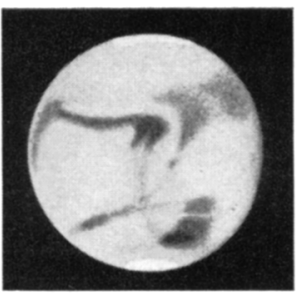

$28^{\circ}$

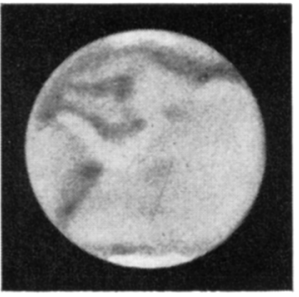

$102^{\circ}$

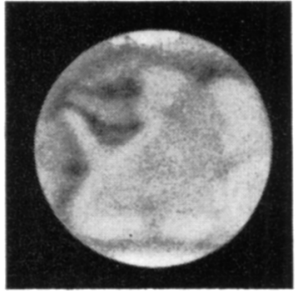

June 22

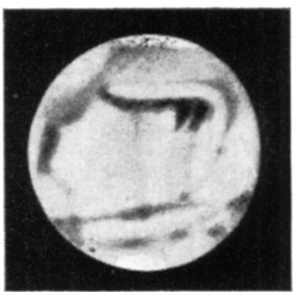

June 30

$344^{\circ}$

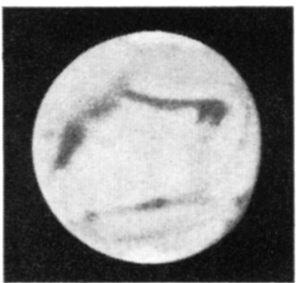

$336^{\circ}$

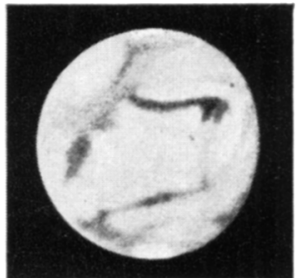

Juby 2

$331^{\circ}$

Opposition dote 1969 Moy 31. Perigee diameter 19"5(June 9)

Heliocentric longitudes $L_{S}=175^{\circ}$ to $182^{\circ}$

Latifude of center of disk $D_{E}=+10^{\circ}$ to $+12^{\circ}$

Fig. 3b. 


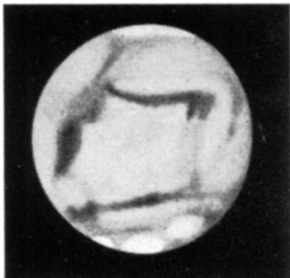

July 3

$331^{\circ}$

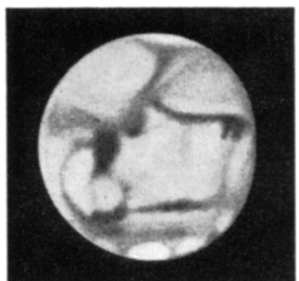

July 4

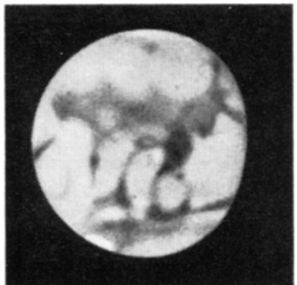

July 8

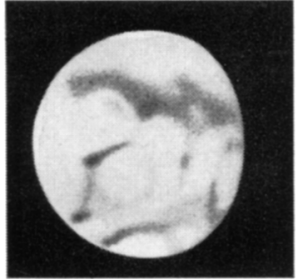

$241^{\circ}$ July 12

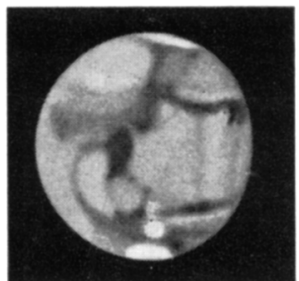

313-

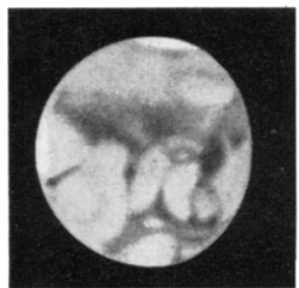

$264^{\circ}$

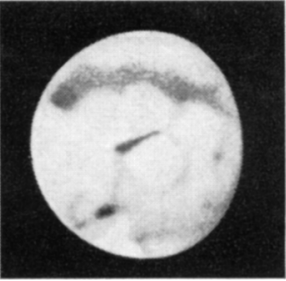

229* July Is

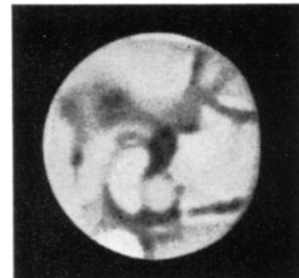

July 6

$289^{\circ}$
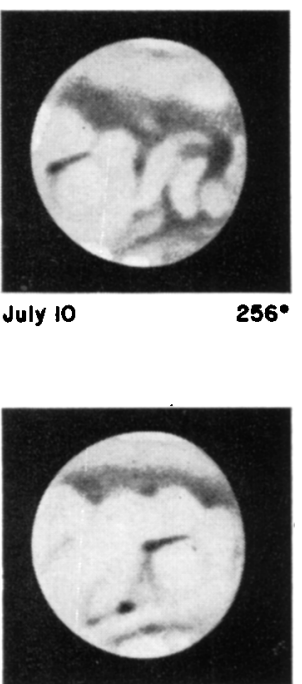

208• July 16

$197^{\circ}$

Opposition date 1969 May 31. Perigee diameter 19"5 (June 9)

Heliocentric longifudes $\quad L_{s}=183^{\circ}$ to $191^{\circ}$

Latifude of center of disk $D_{E}=+12^{\circ}$

Fig. 3c. 
the martian topography which have the characteristic pink or reddish tint of the permanent surface dust. An example is the very stable brighter band on the southern half of Dioscuria-Cydonia running parallel to the Protonilus-Ismenius Lacus-Deuteronilus axis; it was well seen in 1937 (June 4 to 15, July 22) and 1969 (July 1 to 8) and at other favorable oppositions; it is always pinkish, not white, and is well seen through the red filter.

After a month or so of unsteady growth $\left(170^{\circ}<L_{s}<190^{\circ}\right)$ the north polar haze cap assumes a more stable, denser form, and covers the totality of the north polar regions which it will cover solidly throughout the cold season and until the vernal equinox. While the solid frost deposit condenses at the surface under cover of this atmospheric hood, occasional disturbances, perhaps similar to our polar winter storms, are observed at times in the form of wisps or 'tongues' of haze projecting out of the main body into the temperate zone and down to fairly low latitudes; good examples were observed in 1941 (Sept. 19-21, $L_{s}=276^{\circ}$ ) and 1958 (Nov. $4, L_{s}=320^{\circ}$ ) stretching out to $+30^{\circ}$ or $+35^{\circ}$ latitude over the Niliacus Lacus region (Reference [1], Figure 29).

The transition from the residual surface deposit to the large atmospheric haze cap in the range $150^{\circ}<L_{s}<200^{\circ}$ is summarized in Figure 4 where the intermingling of the 1937 and 1969 data points emphasizes the close repeatability of the seasonal pattern.

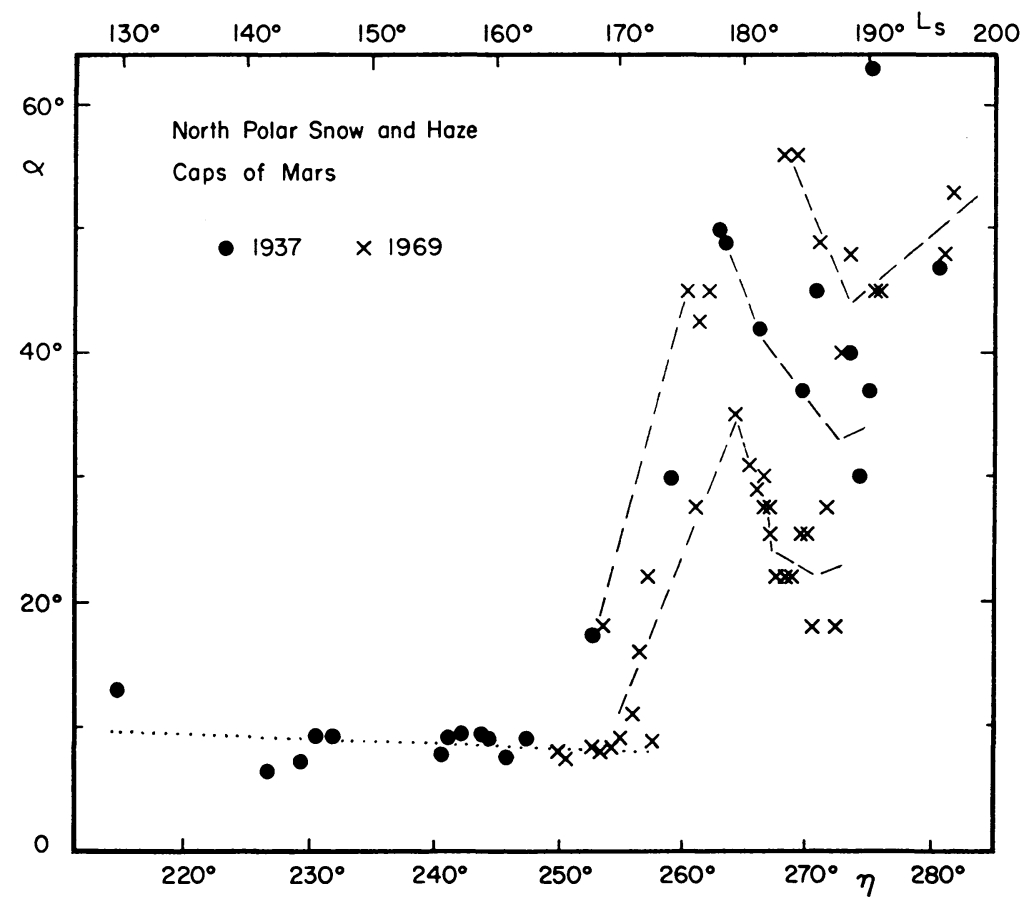

Fig. 4. Regression curve of surface cap and growth curve of haze cap near the autumn equinox of the northern hemisphere of Mars in 1937 and 1939. Lower points after $L_{s}=170$ refer mainly to temporary cloud formations not centered at North Pole. 


\section{Cloud Systems and Widespread Haze on the Disk}

Large persistent cloud systems or widespread haze obscuring the surface details are relatively rare, outside the haze cap over the polar regions and the recurrent condensations at the morning or evening limbs (see Sections 3 and 4). In 1937 a large whitish cloud system was observed on June $25\left(L_{s}=171^{\circ}\right)$ over Phaethontis-Electris-Atlantis and the east end of Mare Cimmerium; gaps in the observations prevented following its motion and evolution, but on July $2\left(L_{s}=177^{\circ}\right)$ the region of Phaethontis-Aonius Sinus was still covered by clouds. On the same date the disk was exceptionally pale and devoid of details east of Sirenum Mare and over the region of Solis Lacus and Tithonius Lacus which were again barely detectable on July 3 and Solis Lacus remained abnormally faint at least until July 8 (compare with May 25-29, Figures $2 a$ and $2 b$ ). In 1969 , on June $10\left(L_{s}=171^{\circ}\right)$ the east end of Mare Cimmerium was covered by a large cloud mass spreading southward from the bright desert area of Zephyria where none was present the day before (Figure $3 \mathrm{a}$ ); scattered remnants of this probable dust storm were observed on the following days over Electris-Phaethontis and perhaps parts of Mare Sirenum (June 11-14). The Solis Lacus region had low contrast on June 19-20 $\left(L_{s}=175^{\circ}\right)$, but poor seeing may have been a contributing factor.

\section{Cloud Activity at the Sunset Limb}

This is a very common and well-documented phenomenon which appears to involve two distinct classes of clouds: (a) bright, white cloud systems in mass motion, which may be high-level convective ice clouds; (b) whitish, recurrent but stationary haze activity which may be low level churning of surface dust. Some areas (Isidis R., Tharsis) seem especially prone to this type of late-afternoon cloud formation. Good examples of type (a) were observed in 1937 (Figure 2a) between May 2 and $6\left(L_{s}=\right.$ $142^{\circ}-144^{\circ}$ ) over Syrtis Major and Libya-Isidis Regio, slowly drifting east at $10 \mathrm{~km} / \mathrm{h}$ ( $12^{\circ}$ in 3 days), and between May 25 and $29\left(L_{s}=153^{\circ}\right)$ over Candor-Ophir, drifting north-east at $13 \mathrm{~km} / \mathrm{h}\left(20^{\circ}\right.$ in 4 days) while spreading and fading over Xanthe-Chryse.

No type (a) cloud was seen in 1969, but bright condensations were frequently seen at the sunset limb (Figures 3a-c), in particular over the Tharsis-Amazonis area, a favorite location for this phenomenon (June 8-14, July 9-16). Similar effects have been observed at several other oppositions, in particular 1939 (July 18-25) and 1954 (Reference [3], p. 116).

\section{Cloud Projecting at the Sunrise Terminator}

This rare, but well-documented phenomenon (Reference [2], plate IX) proves that all early-morning white patches observed on Mars are not frost deposits on the surface; at least some are due to high-altitude icy haze (or in some cases dust layers) whose elevation can be estimated when the cloud is completely or, more often, partly detached from the terminator.

Occasionally, a bright haze or frost patch at sunrise will appear to protrude slightly beyond the terminator (for example see 1937 July 20 and Aug. 2), but most or all of 
the effect is caused by diffraction or seeing spread. However, when the prominence is not significantly brighter than surrounding areas at the terminator the projection must be caused by its elevation above the surface. A remarkable example was observed on July 7, 1969 (Figure 3c) between 305 and 334 UT; this partly-detached cloud was fully developed and immediately noticed, at the beginning of the observation at $305 \mathrm{UT}$; it extended from a faint, diffuse haze patch on the disk, some $15^{\circ}$ southsouth-west of Ismenius Lacus. The prominence was still perceptible at $325 \mathrm{UT}$ and the last trace was seen at 334 UT. The haze patch on the disk remained visible at least until 345 or 350 UT. The geometric elevation of the top of the formation is estimated at some $15 \pm 3$ (p.e.) $\mathrm{km}$; similar observations in the past have given elevations ranging from 5 to $30 \mathrm{~km}$ (Reference [1], p. 48; Reference [2], plate IX).

\section{Acknowledgments}

The 1969 Mars observations and their analysis have been supported by the U.S.A.F. Office of Aerospace Research.

\section{References}

[1] de Vaucouleurs, G.: 1959, Sky Telesc. 18, 484.

[2] de Vaucouleurs, G.: 1954, Physics of the Planet Mars, Faber, London.

[3] Slipher, E. C.: 1962, The Photographic Story of Mars, Sky Publ. Corp., Cambridge.

[4] Antoniadi, E. M.: 1930, La planète Mars, Hermann, Paris. 